\title{
The Sensory Epithelium and Its Innervation in the Mole Rat Cochlea
}

\author{
YEHOASH RAPHAEL, MARC LENOIR, ROMUALD WROBLEWSKI, \\ AND REMY PUJOL \\ Kresge Hearing Research Institute, The University of Michigan, Ann Arbor, Michigan \\ 48109-0506 (Y.R.); INSERM-U. 254, Laboratoire de Neurobiologie de l'Audition, \\ Hôpital St. Charles, Montpellier, France (M.L., R.P.); Department of Pathology, \\ Karolinska Institutet, Stockholm, Sweden (R.W.)
}

\begin{abstract}
The mole rat (Spalax ehrenbergi) burrows throughout its life in subterranean tunnels. Several structural and functional features which adapt the mole rat to its habitat have been discerned. The goal of this study was to elucidate the structural basis for adaptation of the auditory end-organ to an environment where low-frequency acoustical signals prevail. For this purpose, cochleae of adult mole rats were studied with light and electron microscopy. Inner hair cells throughout the cochlea, and outer hair cells in the basal (high-frequency) portion of the cochlea, were similar in structure to those seen in other mammals. In contrast, outer hair cells in the apical (low-frequency) portion displayed unique structural features. These features resembled the structure of inner hair cells or immature outer hair cells. The innervation of outer hair cells was most uncommon, in that classical medial efferent innervation was not found throughout the cochlear spiral.
\end{abstract}

Key words: Spalax, organ of Corti, hair cells, tectorial membrane, stereocilia, efferent innervation

The mole rat, Spalax ehrenbergi, is a completely blind rodent (Haim et al., '83), which burrows throughout its life in dark subterranean tunnels (Nevo, '79). The acoustic environment in a subterranean habitat supports propagation of low-frequency signals whereas high frequencies are poorly transmitted. The sound frequency known to propagate best in underground tunnels is lower than $0.5 \mathrm{kHz}$ (Heth et al., ' 86 ). This frequency $(0.5 \mathrm{kHz})$ is similar to that of the mole rat courtship calls (Heth et al., '88). Audiograms obtained by behavioral conditioning have established that the audible frequencies of the mole rat range between 0.02 and $10 \mathrm{kHz}$, with best sensitivity at $0.5-1 \mathrm{kHz}$ (Bruns et al., '88; Bronchti et al., '89). The upper end of this frequency range is the lowest known among mammals (Heffner and Heffner, '82).

Recent studies on the mole rat auditory system reported a unique middle ear morphology and suggest adaptation to low-frequency hearing and to communication via very low-frequency vibrations or vocalizations (Bruns et al., '88; Rado et al., '89). The mole rat cochlea is divided into two distinct subsystems, basal and apical (Bruns et al., '88). It has been shown that while the basal organ of Corti is similar to that of other mammals, the apical portion differs in dimensions of hair cells, stereocilia, tectorial membrane (TM), and basilar membrane, relative to other mammals (Bruns et al., '88; Burda et al., '89). These data suggest that the apical subsystem of the mole rat organ of Corti is highly adapted for low-frequency hearing. Specialized low-frequency hearing is also indicated by functional mapping of subcortical auditory pathways (Bronchti et al., '89). Taken together, these studies indicate that the range of frequencies audible to the mole rat is lower than is known in any other mammal.

The goal of the present study was to elucidate, at the ultrastructural level, the morphological basis for poor high-frequency and enhanced low-frequency hearing in the mole rat. For this purpose, the sensory epithelium, its innervation, and the TM were studied, with transmission (TEM) and scanning (SEM) electron microscopy. The results are presented and discussed in comparisons between basal and apical portions of the cochlea, as well as between the organ of Corti of the mole rat and other mammals.

\section{MATERIALS AND METHODS}

Mole rats are not readily available for research as they do not breed in captivity and are difficult to capture. The present results are based on an investigation of 6 adult mole rat cochleae, obtained from 5 different animals. Animals

Accepted September 11, 1991.

Address reprint requests to Dr. Yehoash Raphael, University of Michigan, Kresge Hearing Research Institute, $1301 \mathrm{E}$. Ann St., Ann Arbor, MI 48109-0506. 
were anesthetized with Equithesin and intravascularly perfused with Karnovsky fixative in $0.1 \mathrm{M}$ cacodylate buffer, $\mathrm{pH}$ 7.4. The tympanic bullae were then removed, the otic capsules opened, and the cochleae immersed in the same fixative for at least 1 hour.

Tissue specimens were postfixed in $1 \%$ aqueous osmium tetroxide for 1 hour for TEM or 10 minutes for SEM. Specimens were subsequently dehydrated in graded series of ethanol (35\% to $100 \%)$.

For SEM, cochleae were dissected in $70 \%$ ethanol to expose the organ of Corti, critical point dried in $\mathrm{CO}_{2}$, coated with gold, and observed with a Jeol $25 \mathrm{~S}$ or Philips 505 scanning electron microscope. For TEM, tissue was dehydrated through graded series of ethanol and embedded in Epon or Spurr's resin. The plastic block was then divided into fragments, each fragment containing half a turn of the cochlear duct. These fragments were further trimmed to remove bony parts and then sectioned with a diamond knife. Semi-thin $(1 \mu \mathrm{m})$ sections were stained with toluidine blue and examined with a light microscope (LM). Grids were stained with lead citrate and uranyl acetate and analyzed on a Philips EM 301 or Philips EM 400T electron microscope.

\section{RESULTS}

We refer to the region of the hook and 1st turn as basal (high-frequency) cochlea, and to the second and third turns as apical (low-frequency) cochlea.

\section{Base of cochlea}

In the basal portion of the cochlear duct (Fig. 1), the general cellular organization of the organ of Corti resembles that of other mammals. Inner hair cells (IHCs) form a single row, whereas cylindrical outer hair cells (OHCs) are arranged in three rows (Figs. 1, 2A). This organization is also present at the beginning of the middle cochlear turn (Fig. 2B). The shape of the tunnel of Corti and the fluid spaces around the OHCs (Fig. 2C) are similar to those found in other mammals.

The pattern of OHC stereocilia varies according to location along the cochlear spiral. In the lower-basal cochlea, $\mathrm{OHC}$ stereocilia form a broad $\mathrm{V}$ with an near-right angle (Fig. 3A). Each V-shaped bundle contains 5-6 rows of stereocilia, decreasing in length from lateral to medial (Fig. $3 B, D)$. In the extreme basal region, stereocilia from two adjacent hair cells appear very closely apposed (Fig. 3B). In the basal region, the pattern is orderly, although occasional irregularities are found, such as the presence of a 4th-row OHC (Fig. 3A).

A surface view of the reticular lamina (apical surface of the epithelial mosaic of the organ of Corti) reveals that supporting cells are positioned between the hair cells (Fig. $3 \mathrm{~A}$. A lateral view of the $3 \mathrm{rd}$ row of OHCs shows that the phalangeal process of each Deiters cell projects obliquely to the reticular lamina, reaching the surface four OHCs further-on towards the apex (Fig. 3C).

In the basal cochlear turn, the TM surface facing the hair cells is relatively smooth and imprints of stereocilia of the three rows of OHCs can be seen (Fig. 4A,B). Nevertheless, a structure similar to Hardesty's membrane was not found throughout the TM of the mole rat cochlea. No IHCstereocilia imprints can be found. The lateral border of the TM is band-like (see Lim, '72). A dense filamentous substance is present around the tips of stereocilia in contact with the TM (Fig. 4C). A dense filamentous material is also found at the point of contact between the shaft of one stereocilium and the tip of its neighbor (Fig. 4D).

Cross-sections in a nearly mid-modiolar plane reveal typical cellular organization of the OHC region (Fig. 5A). The intercellular junctions between $\mathrm{OHCs}$ and supporting cells contain prominent adherens-type complexes with asymmetric distribution of filaments. OHCs are surrounded by extracellular fluid spaces (space of Nuel). The portion of a Deiters cell in contact with the base of an OHC contains numerous mitochondria and cytoskeletal filaments. This contact area often extends above the level of the OHC nucleus. Mitochondria are distributed in the infracuticular region and along the cell membrane of $\mathrm{OHCs}$. As previously reported, a single layer of subsurface cisternae (SSC) is located along the lateral aspect of OHCs (Raphael and Wroblewski, '86). SSC appear to be connected to the plasma membrane via "arms" or "pillars" (Fig. 5B).

Mid-modiolar sections of spiral ganglion cells in Rosenthal's canal reveal myelinated and unmyelinated fibers. These most likely correspond to afferents and lateral efferents, respectively. The former are sectioned tangentially and the latter are sectioned perpendicular to their long axis (Fig. 5C). Artifact-related fractures permit inspection of the organ of Corti below the reticular lamina (Fig. $2 \mathrm{C}$ ). In these fractured regions, isolated bundles of thin nerve fibers are seen crossing radially on the floor of the tunnel of Corti. In other mammals, fibers which cross the organ of Corti on the floor of the tunnel are spiral afferent dendrites of type II neurons that contact OHCs (Spoendlin, '73). In contrast to other mammals, no nerve fibers cross the tunnel of Corti above the floor level. The longitudinal nerve bundle located along the basal portion of the inner pillars (Fig. 2C) probably corresponds to the spiral tunnel bundle, which in other mammals contains lateral and medial efferent fibers (Wright, '75).

An area measuring about $1 \mathrm{~mm}$ in length, consisting of over 50 outer hair cells, was serially sectioned in one cochlea and carefully examined. No typical efferent nerve endings can be identified at the bases of OHCs. In contrast, in the serially sectioned cochlea as well as in other ears, most of the nerve endings found in contact with $\mathrm{OHCs}$ appear to be afferents, based of their small size and paucity of vesicles (Fig. 6A). The synaptic area between afferents and $\mathrm{OHCs}$ contains symmetrical densities, endocytotic profiles, and coated vesicles, but synaptic bodies were not found. Some vesicle-containing terminals are found, but the density of the vesicles is low and they are not clustered at the synapse. These terminals are not apposed by postsynaptic cisternae in the $\mathrm{OHC}$.

The pattern of innervation of basal turn IHCs is similar to other mammals (Fig. 6B). The basal pole of IHCs is surrounded by numerous afferent nerve-endings. Synaptic bodies are seen apposed to afferent contacts (Fig. 6B inset). Efferent endings make axo-dendritic contacts with afferent fibers in the inner spiral bundle. A few efferents make contact with IHCs (Fig. 6B), but do not appear to be synapsing with them.

\section{Apical cochlea}

In the middle (Fig. 7A) and 3rd turns, Deiters cells appear to have very small areas of contact with the basilar membrane. In the middle turn OHCs are long and straight (Fig. 7A). The lateral membranes of different $\mathrm{OHCs}$ are in contact in various areas (Fig. 7A,C,D). Where $\mathrm{OHC}-\mathrm{OHC}$ 


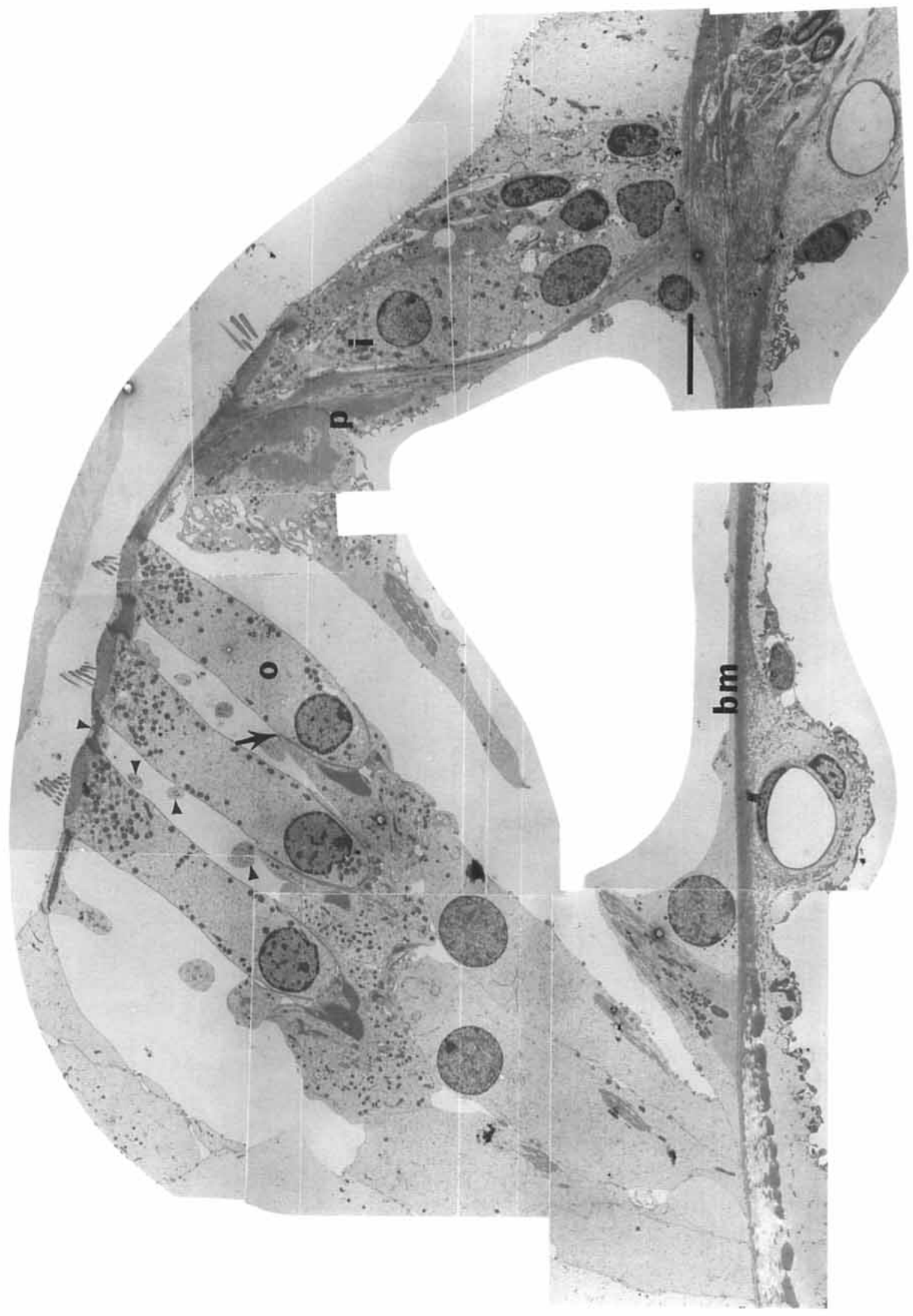

뭃 륨

क्षे

蛋

产焉

需荧

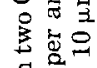

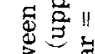

证西

范家

究 ⿷匚

承荌范

晋

旅

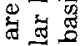

喓通

哓

․․ำ

密总奇

i.

䨌

8

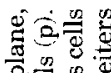

可

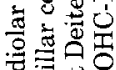

㛡

要这跑

릉

鸟密

Фี

品事

焉要

式苍它

웡 क

농용

ชิ

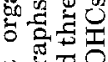

대유

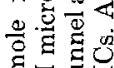

¿

田寻

퐁

$\sum$ 目

过

的氙焉

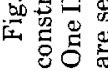



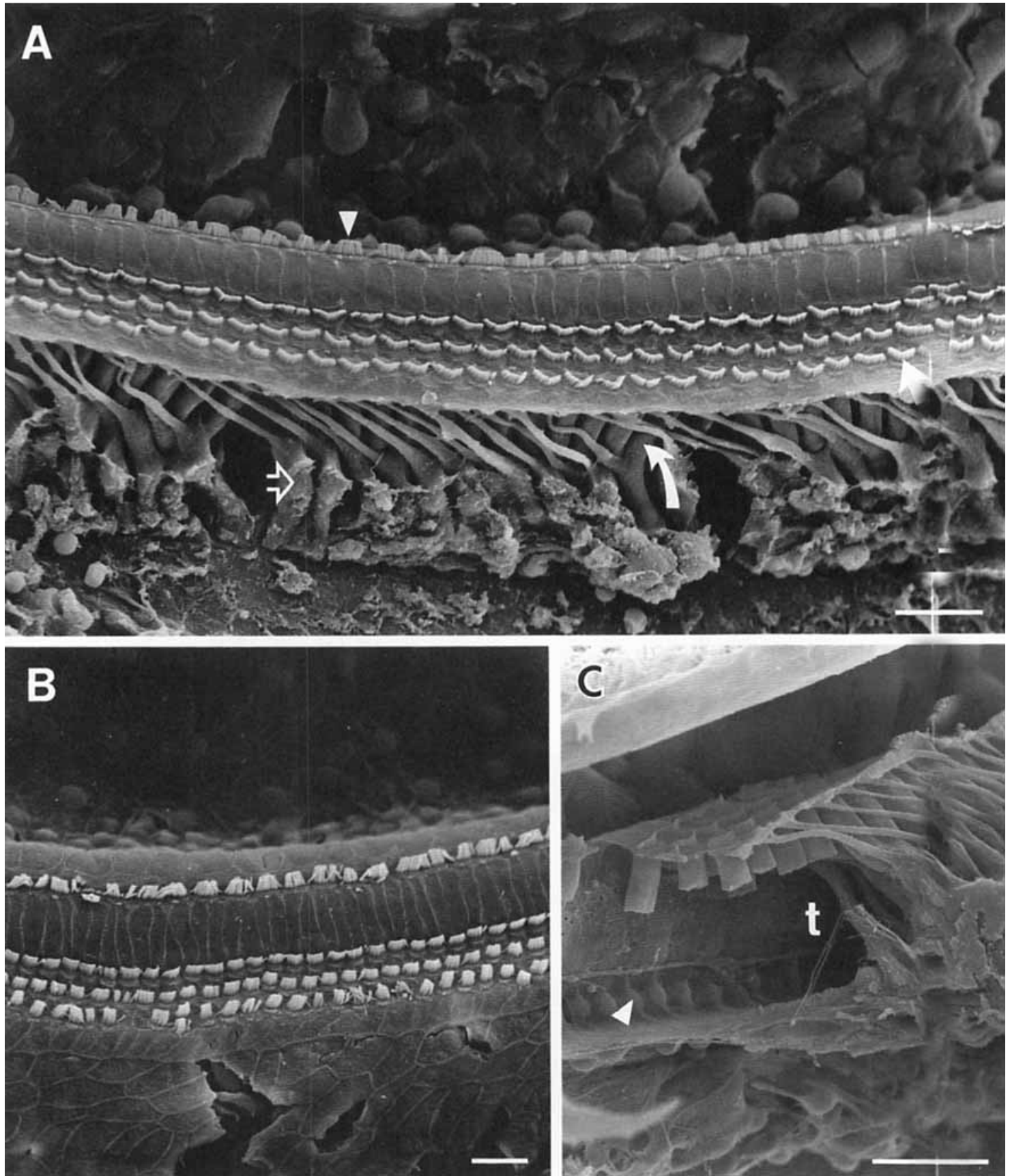

Fig. 2. SEM micrographs of mole rat organ of Corti in basal portion of cochlea. A: IHCs form a single row (arrowhead = IHC stereocilia), whereas $\mathrm{OHCs}$ form three rows (straight arrow $=\mathrm{OHC}$ stereocilia). OHCs are cylindrically shaped (curved arrow) and Deiters cells (open arrow) extend apical processes to the reticular lamina. Note orderly organization of tissue. B: SEM view of beginning of middle cochlear

contacts occur, the extracellular fluid-spaces of Nuel are eliminated. Direct $\mathrm{OHC}-\mathrm{OHC}$ contacts occur between neigh boring cells of the same row and those of adjacent rows (Fig. 7D). Such contacts have not been described in other mammals.

The distribution and organization of SSC in OHCs of the apical turn are similar to SSC in the basal turn. In both turn. Stereocilia are taller than in A and tissue is well organized. C: In basal portion of cochlea fluid spaces surround OHCs. Longitudinal nerve bundles (arrowhead) run near inner pillars and extend to tunnel of Corti ( $t$ ) at its floor, but no nerves are seen crossing above floor level. Bars $=25 \mu \mathrm{m}$.

regions, conspicuous arms extend from the $\mathrm{SSC}$ into the membrane (Fig. 7B). No difference is seen between SSC in areas where the lateral membrane is in contact with extracellular fluid (Fig. 7B) and areas where two OHCs are in contact with each other (Fig. 7C).

In the upper-basal cochlear turn the V-formation of the stereociliary bundle is maintained although the angle is 

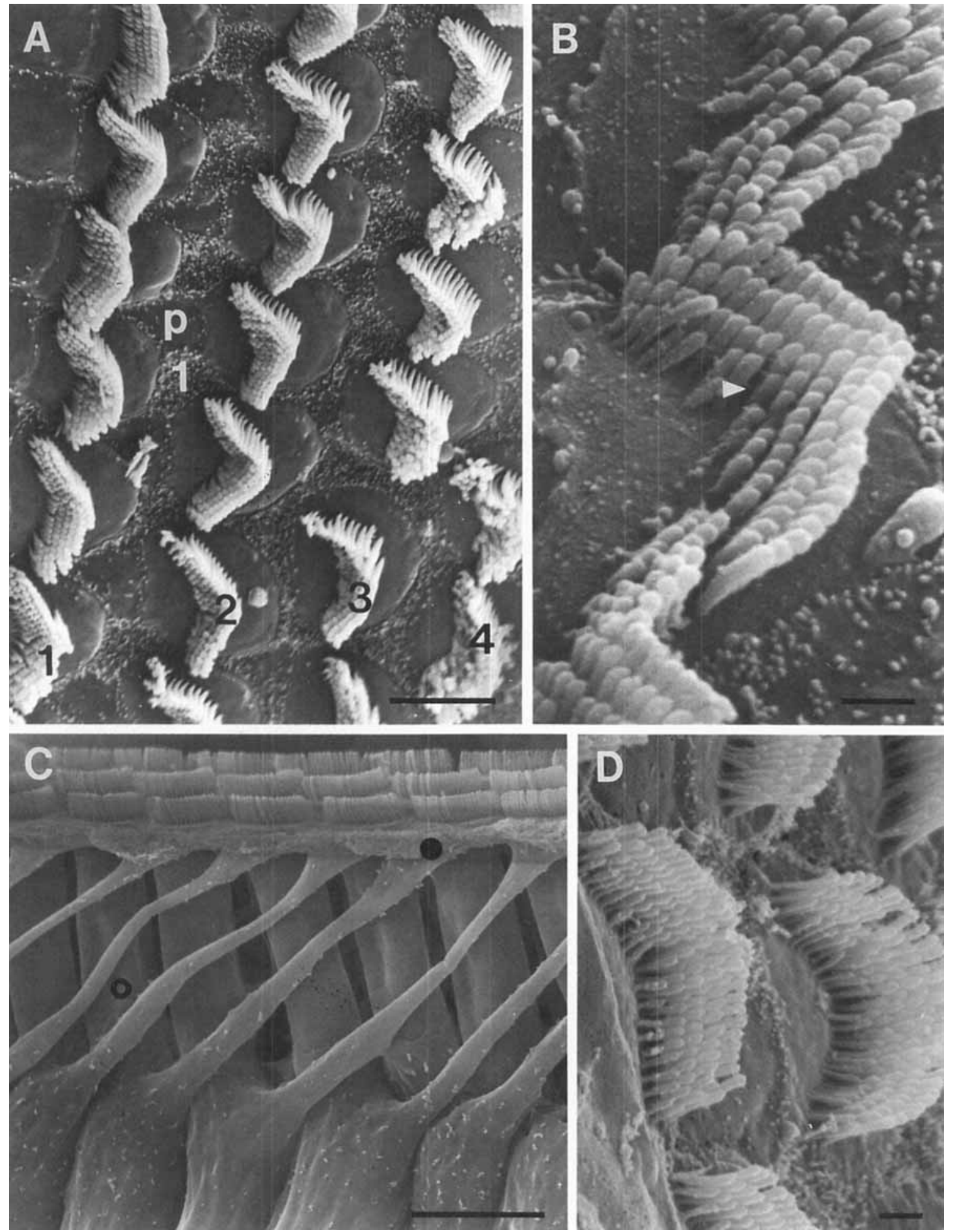

Fig. 3. SEM micrographs of $\mathrm{OHC}$ region at lower-basal portion of cochlea. A: Orderly pattern of reticular lamina shows three $\mathrm{OHC}$ rows $(1,2,3$, from medial to lateral) with a 4th-row $\mathrm{OHC}(4)$ occasionally present lateral to the 3 rd $\mathrm{OHC}$. First row $\mathrm{OHCs}$ are separated by outer pillar heads (p) while 2nd and 3rd rows are separated by Deiters cell (white 1 shows 1st-row Deiters cell). Stereocilia are arranged in 5-6 rows and form broad $\mathrm{V}$ (angle close to $90^{\circ}$ ). B: Stereocilia of two adjacent hair cells in extreme basal region appear very closely apposed.
Several stereocilia are connected by side-links (arrowhead). C: Lateral view showing 3rd-row $\mathrm{OHCs}$ and Deiters cells. Fluid spaces surround cylindrical body of OHCs. Note that a given Deiters cell supports one $\mathrm{OHC}(\mathrm{o})$ and sends its phalangeal process obliquely to reticular lamina, reaching the surface four OHCs away (black dot). D: Basal $\mathrm{OHC}$ stereocilia (near hook) seen from medial aspect, arranged in 5 rows. Bars: $\mathrm{A}=5 \mu \mathrm{m} ; \mathrm{B}=1 \mu \mathrm{m} ; \mathrm{C}=10 \mu \mathrm{m} ; \mathrm{D}=1 \mu \mathrm{m}$. 


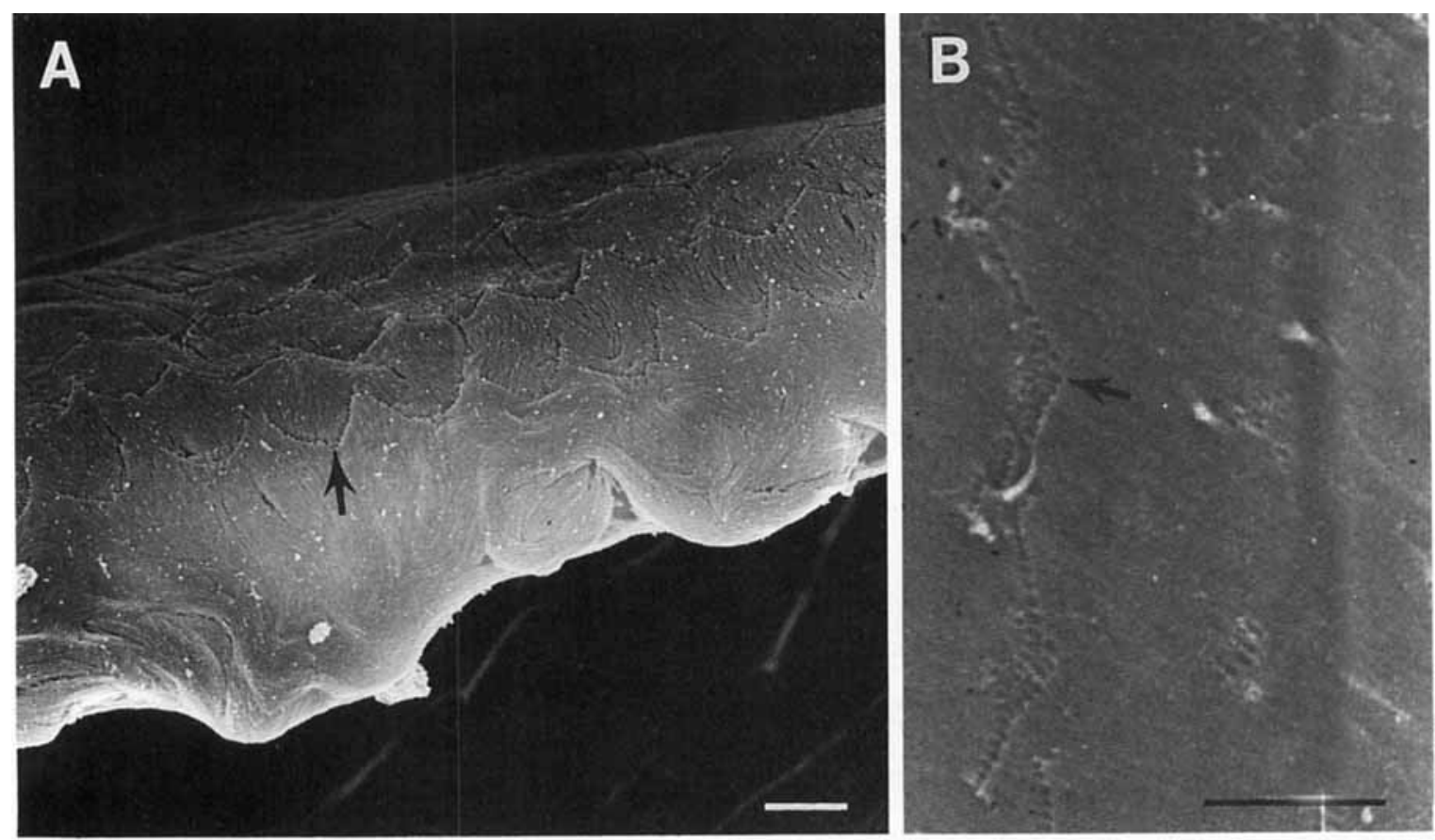

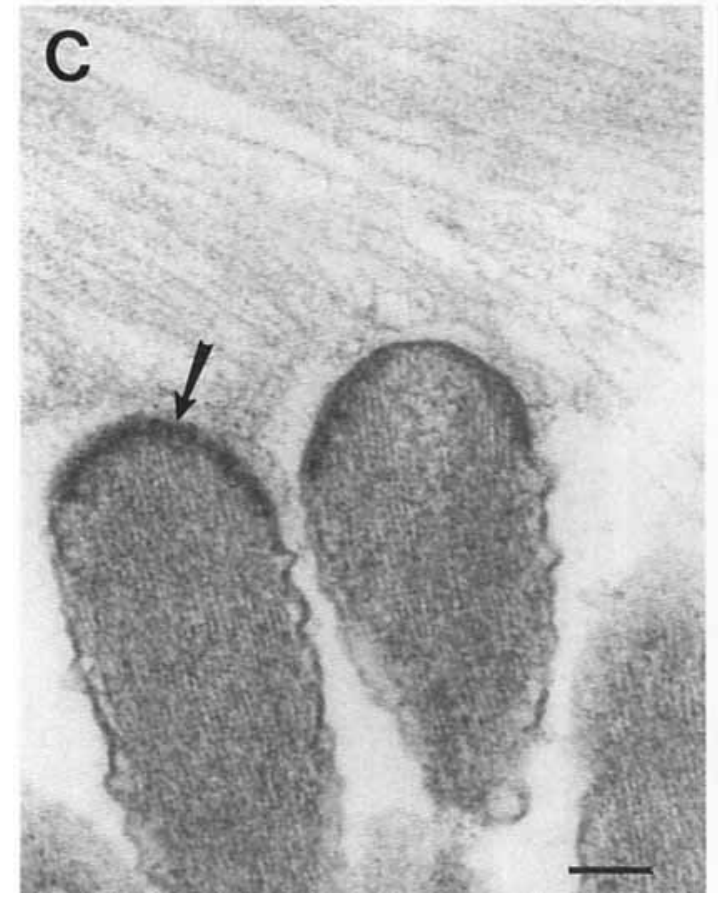

Fig. 4. SEM (A, B) and TEM (C, D) micrographs show area of contact between stereocilia and tectorial membrane (TM). A: In basal cochlear turn, surface of TM facing reticular lamina is smooth, and contains imprints of OHC stereocilia-tips (arrow). B: Imprints consist of 1 or 2 lines (arrow), corresponding to 2 tallest rows of stereocilia. C:

acute (Fig. $8 \mathrm{~A}$ ) but in more apical regions the $\mathrm{V}$ arrangement can no longer be found (Fig. 8B). Stereocilia of OHC in the lower apical turn appear very tall and the bundles are arranged similar to stereocilia of IHCs (Fig. 8C,D). In the uppermost half turn OHCs are absent (Fig. 8E).

The cytoarchitecture in the third (apical) turn of the mole rat cochlea is not as orderly as in the base. The rows of

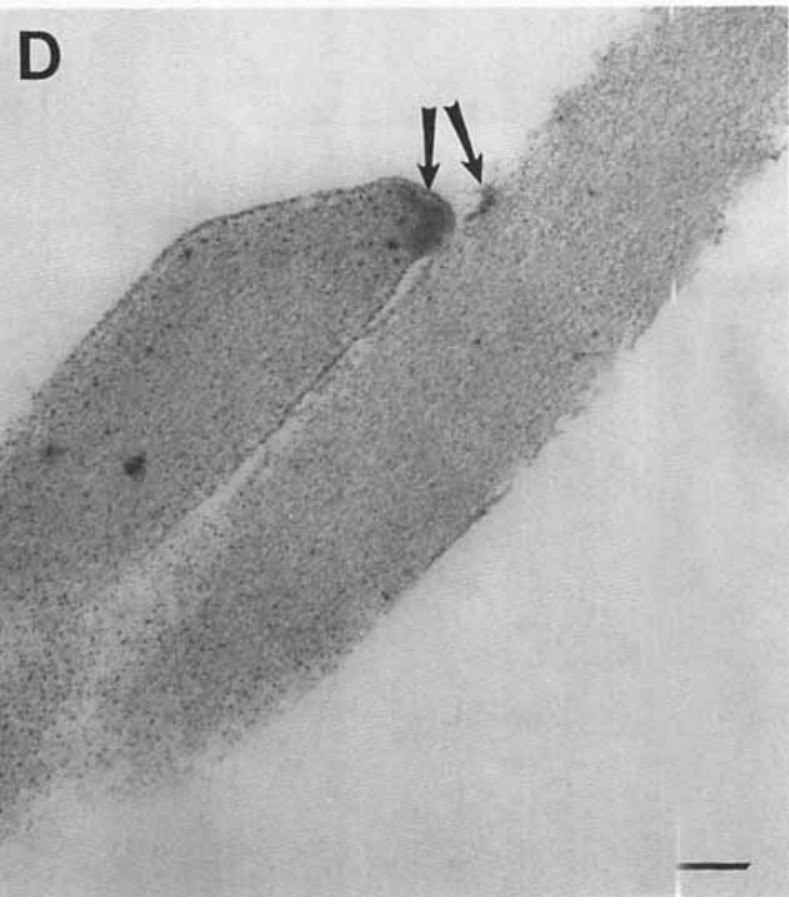

Tips of stereocilia contain dense filamentous substance within cytoplasm (arrow). D: Contact points between 2 neighboring stereocilia (arrows) also contain dense filamentous material. Bars: $\mathrm{A}=10 \mu \mathrm{m} ; \mathrm{B}=$ $5 \mu \mathrm{m} ; \mathrm{C}=0.1 \mu \mathrm{m} ; \mathrm{D}=0.1 \mu \mathrm{m}$.

OHCs are not well organized and a few cells are missing (Fig. 9A, compare with 3A). Missing cells are replaced by phalangeal scars. TEM analysis of the 3rd turn reveals some nearly spherical OHCs (inset in Fig. 9A). A relatively disorganized epithelium can also be seen in the upper middle turn (results not shown). Higher in the apical turn, $\mathrm{OHCs}$ are no longer present, with the exception of very few 

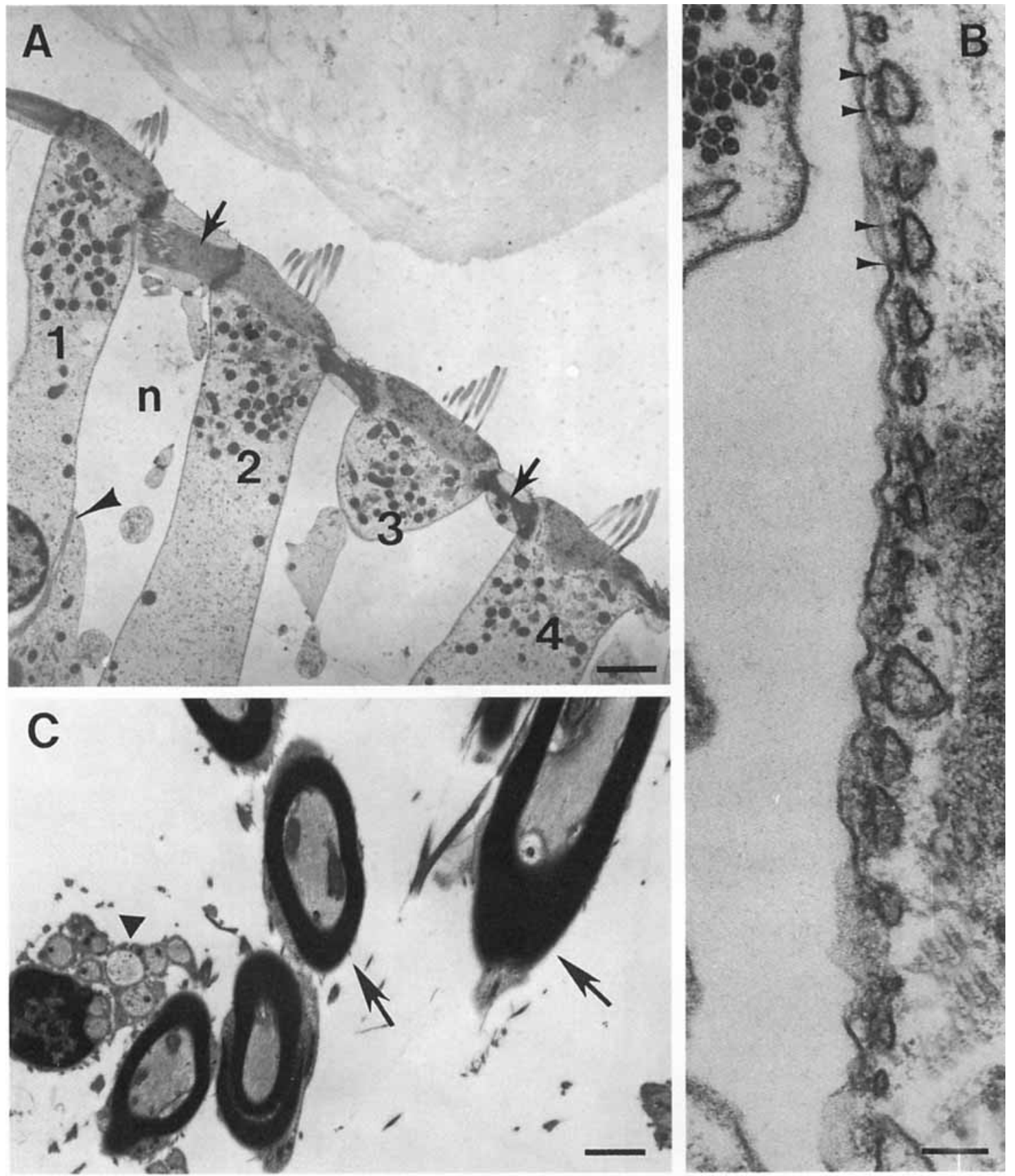

Fig. 5. TEM cross-sections in basal turn. A: At level of reticular lamina $4 \mathrm{OHCs}$ are seen. Adherens-type junctions between OHCs and supporting cells are asymmetric, with more filaments in supporting cells (arrows) than in OHCs. Mitochondria are distributed in infracuticular region and along cell membrane. OHC bodies are surrounded by fluid spaces ( $n$ ). Contact between $\mathrm{OHC}$ and Deiters cell reaches supranuclear level (arrowhead). Deiters cell contains numerous mito-

atypical deformed cells (Fig. 9B). On the other hand, IHCs are present, arranged in one or two rows (Fig. 9B). Cross sections of the apical cochlea confirm the presence of two IHC rows, located medial to the inner pillar cell (Fig. 9C). No Deiters cells are seen in cross sections of the organ of Corti at this region (Fig. 9D).

Throughout the cochlea, $\mathrm{OHC}$ stereocilia are strongly embedded in the TM. In the second and third turns, the chondria and cytoskeletal filaments in contact area. B: One layer of subsurface cisternal (SSC) lines lateral membrane of OHC. "Arms" extend laterally from SSC to plasma membrane (arrowheads). C: Mid-modiolar sections of spiral ganglion cells in Rosenthal's canal. Myelinated fibers are sectioned longitudinally or obliquely (arrows): unmyelinated fibers are sectioned perpendicular to their long axis (arrowhead). Bars: $\mathrm{A}=2.5 \mu \mathrm{m} ; \mathrm{B}=0.1 \mu \mathrm{m} ; \mathrm{C}=1 \mu \mathrm{m}$.

underside of the TM appears rough and fibrillar (Fig. 10A). In some cases, removing the TM from the epithelial surface results in detachment of stereocilia from their anchoring point in the cuticular plate (Fig. 10A,C). TM removal permits inspection of 5 neatly organized rows of stereocilia at the level of the $\mathrm{OHC}$ surface (Fig. 10C). In other cases TM removal results in detachment of large fibers from the underside of the TM. These fibers remain attached to the 

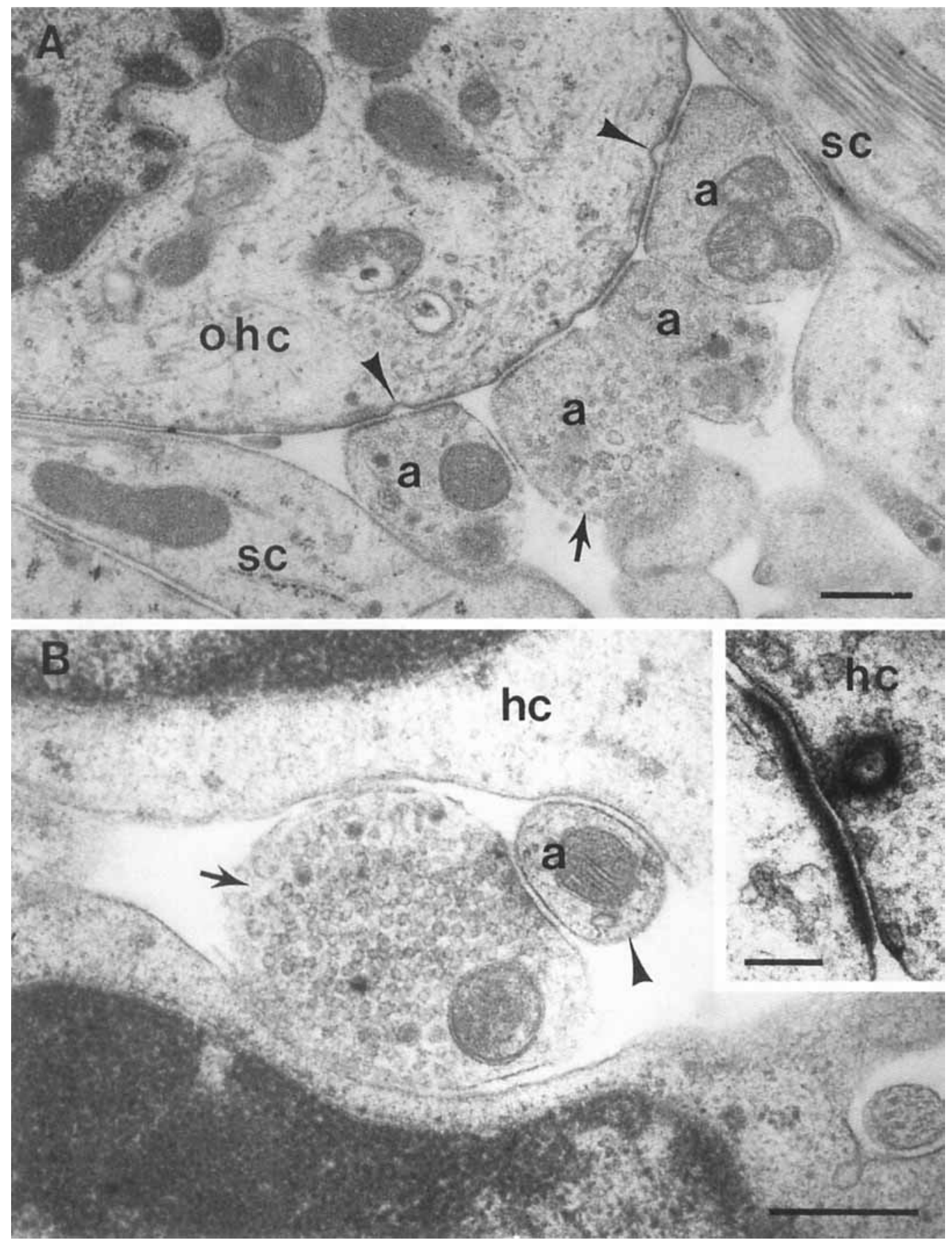

Fig. 6. TEM micrograph of nerve terminals on basal $\mathrm{OHC}(\mathrm{A})$ and IHC (B). A: Four small nerve endings (a) on an OHC (ohc) appear like afferents. Terminals contain few (arrow) or no vesicles. Synaptic area contains endocytotic profiles (arrowheads) and several coated vesicles in $\mathrm{OHC}$ side, and symmetrical dense areas. Terminals are not apposed

tips of the stereocilia (Fig. 10B). TEM analysis reveals a very prominent dense material at the tips of the stereocilia (Fig. 10D). Imprints of stereocilia are not seen in the helicotrema region of the TM, in accordance with the absence of $\mathrm{OHCs}$ in this region (results not shown).

The innervation of $\mathrm{OHCs}$ in the middle (Fig. 11A) and apical (Fig. 11B) cochlear turn is similar to that in the basal turn. No efferents are to be seen in association with $\mathrm{OHCs}$ by SSC on OHC side of synapse. OHC is also in contact with supporting cells (SC). B: IHC is innervated by afferent fiber (arrowhead) while efferent ending (arrow) make axo-dendritic contacts with afferent. Inset: Synaptic bodies are typical of afferent synapses on IHC (hc) side of synapse. Bars: $\mathrm{A}=0.5 \mu \mathrm{m} ; \mathrm{B}=0.5 \mu \mathrm{m}$; inset $=0.2 \mu \mathrm{m}$.

throughout the organ of Corti. Synaptic bodies are observed opposing afferent synapses in some but not all sections (Fig. $11 \mathrm{~B}$, inset).

\section{DISCUSSION}

Our ultrastructural analysis provides detailed information on the morphology of the organ of Corti in the mole rat. 


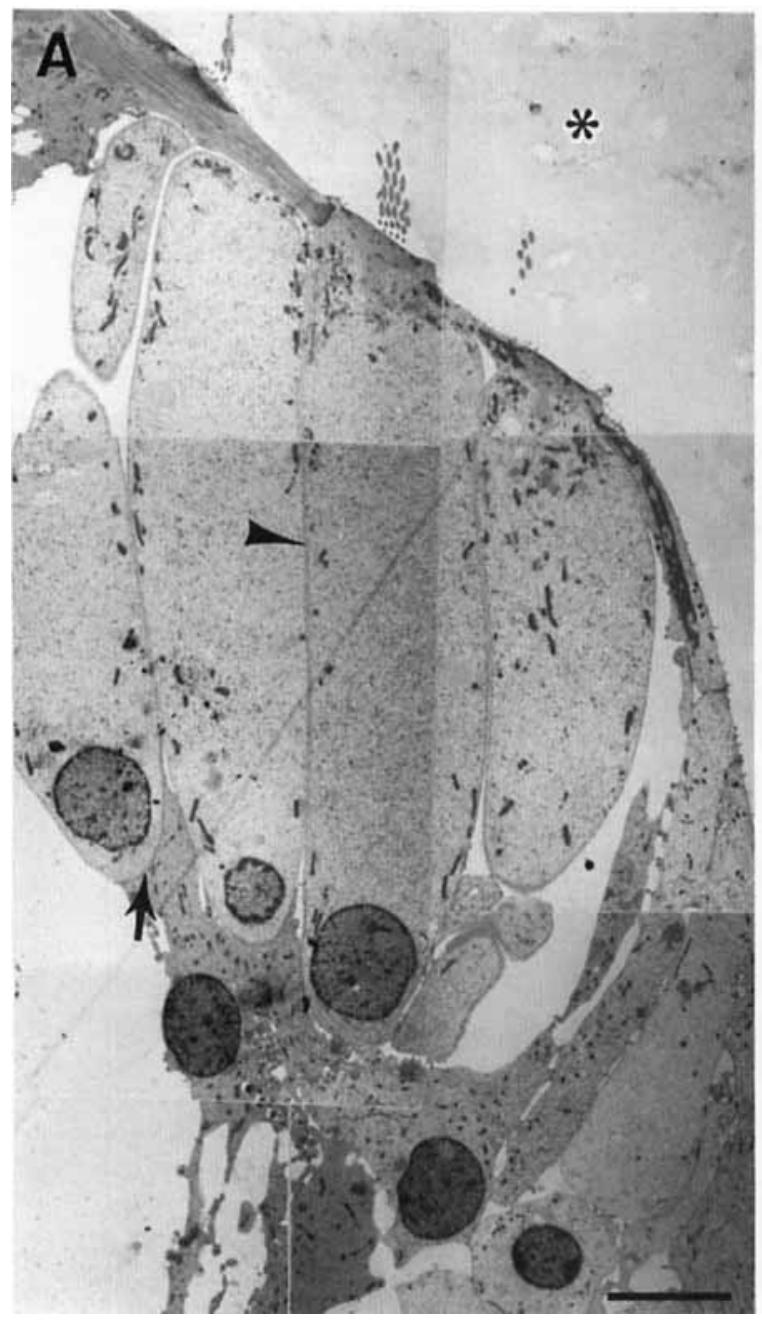

Fig. 7. Apical mole rat cochlea sectioned for TEM at mid-modiolar plane (A) and at a plane parallel to basilar membrane (B-D). A: Mid-modiolar cross-section of OHCs in upper-middle turn. OHC-OHC contacts (arrowhead) are present along lateral membrane of all four $\mathrm{OHCs}$ present. Stereocilia are in contact with TM (asterisk). OHCDeiters cell contact is limited to small area (arrow). B: SSC line lateral membrane in apical turn OHCs. Arms extend from SSC into membrane

Comparison with other mammals shows several uncommon or even unique features, which may contribute to the reduced high-frequency hearing of the mole rat (Bruns et al., '88). Our ultrastructural analysis confirms a previous report which showed considerable differences between the basal and apical portions of the mole rat cochlea, and that the apical cochlea has several features which are atypical or unique among mammals (Bruns et al., '88). Moreover, we point out that not only is the apical mole rat cochlea atypical, but so is the basal cochlea, mainly in that OHCs appear devoid of neural supply from the medial efferent fibers.

Some of the findings about the structure of apical OHCs resemble reports of abnormal hair cells in other mammals after inner ear insult or poor fixation. Because the basal cochlea is more susceptible to insults and fixation artifacts than the apical cochlea, healthy appearance of basal OHCs is generally a reliable indicator for adequate fixation and preservation. The well preserved basal OHCs in our material (Figs. 1-6) indicate that adequate fixation has been (arrowheads). Microtubules (arrow) extend from SSC medially. C: SSC in area of OHC-OHC contact, lining membrane of both OHCs. D: Direct contacts occur between $\mathrm{OHCs}$ of 1 st (1) and 2nd (2) rows (arrow), between $\mathrm{OHCs}$ of same row and between $\mathrm{OHCs}$ of 2 nd and 3rd rows (arrowhead). Note that some intercellular fluid space is present. Bars: $\mathrm{A}=10 \mu \mathrm{m} ; \mathrm{B}=0.1 \mu \mathrm{m} ; \mathrm{C}=1 \mu \mathrm{m} ; \mathrm{D}=1 \mu \mathrm{m}$.

achieved. Moreover, the flask-shaped apical OHCs are neither ruptured nor vacuolated. In addition, our analysis of several cochleae from different ages of mole rats yielded similar results. We therefore interpret our findings as typical and not a result of fixation or damage artifact.

As reported by Bruns et al. ('88), one striking feature of the mole rat apical cochlea is a poorly organized epithelial mosaic. Slight irregularities in the epithelial organization have also been found in the apical turn of several other mammals (Kawabata and Nomura, '78; Lenoir et al., '87). The bat auditory epithelial mosaic, which codes for extremely high frequencies, is highly ordered throughout the cochlear duct (Vater et al., '91a). This suggests that a highly organized epithelium in the organ of Corti is important for high-frequency hearing.

\section{Inner hair cells}

The mole rat IHCs appear similar in size and shape to those of other mammals. The pattern of IHC innervation is 

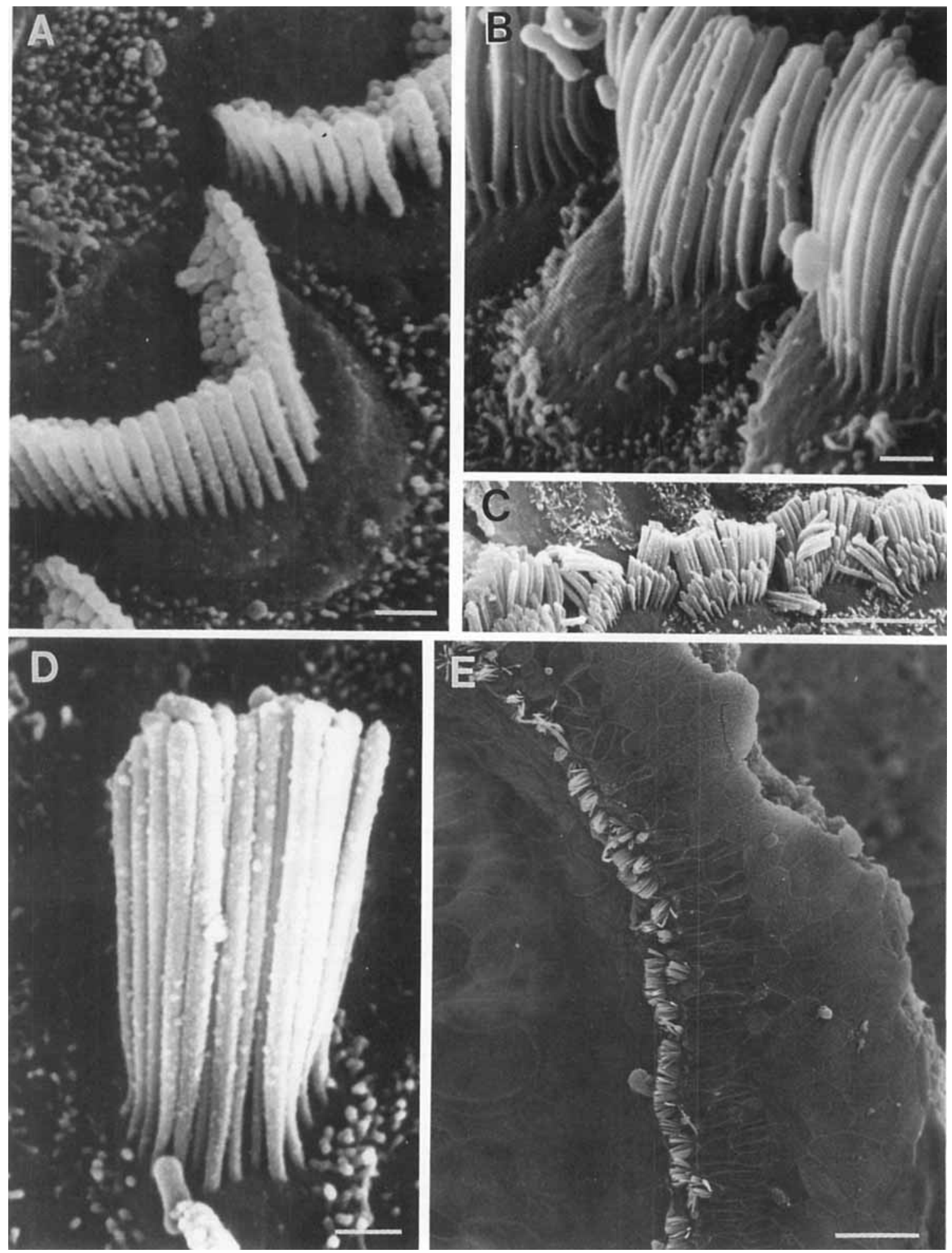

Fig. 8. SEM micrographs of OHC stereocilia in upper-basal (A), middle (B), lower-apical (C, D), and higher-apical turns (E). A: In upper-basal turn stereocilia are arranged in five rows organized in a V-shaped bundle. B: In middle turn stereocilia are taller and V-shape is not evident. C: Seen from medial side, OHC stereocilia in middle turn are arranged similar to IHC stereocilia. D: Stereocilia in apical turn are very tall. E: Midway through apical turn, $\mathrm{OHCs}$ are absent and $\mathrm{IHCs}$ are arranged in one or two rows. Bars: $\mathrm{A}=1 \mu \mathrm{m} ; \mathrm{B}=1 \mu \mathrm{m} ; \mathrm{C}=10 \mu \mathrm{m}$; $\mathrm{D}=1 \mu \mathrm{m} ; \mathrm{E}=25 \mu \mathrm{m}$. 

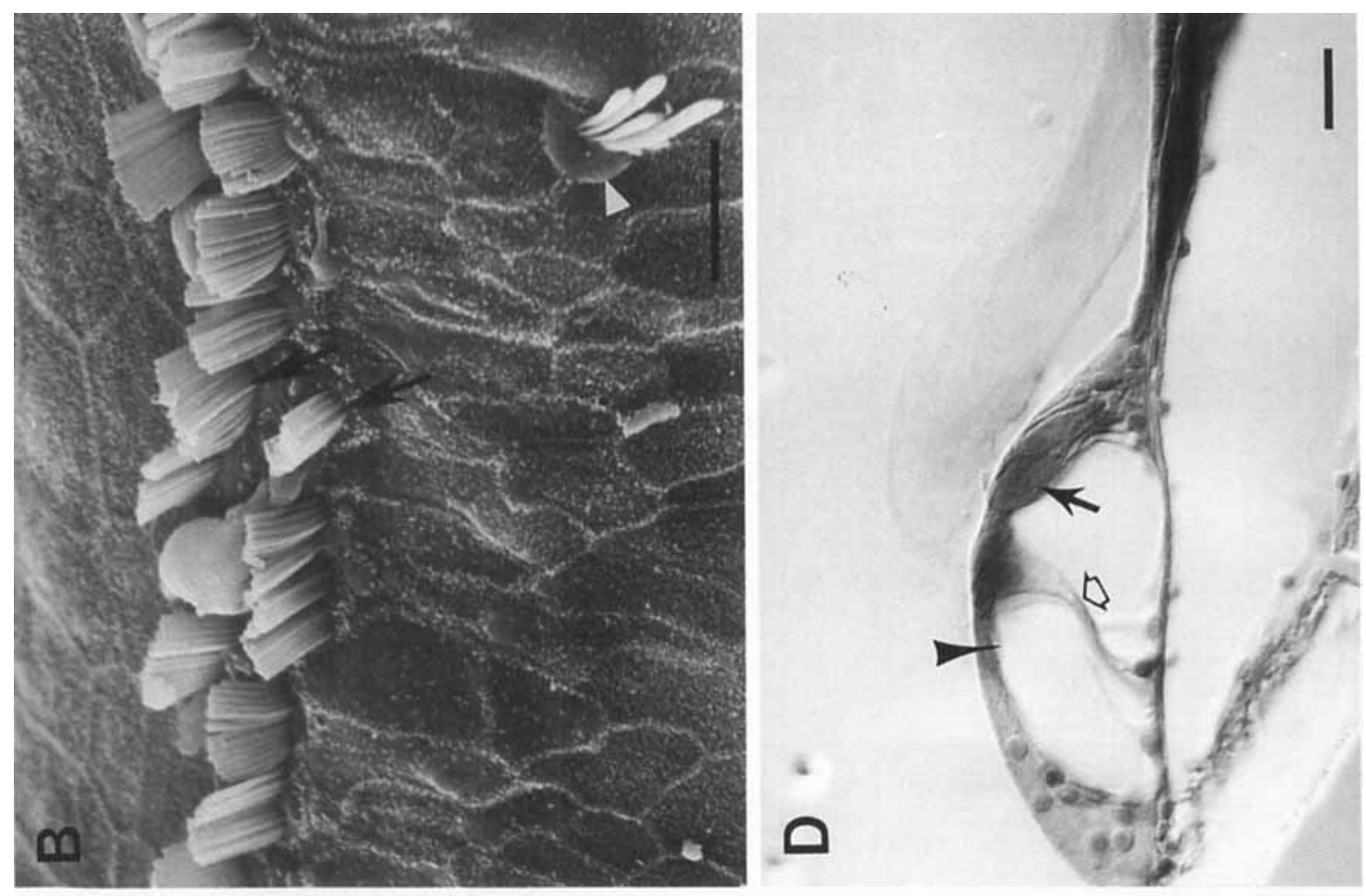

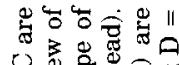

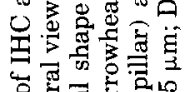

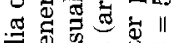

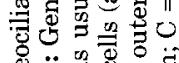

递苛骂

क人

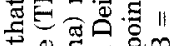

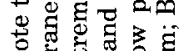

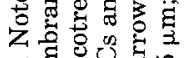

定:

\%

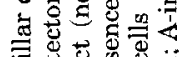

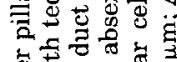

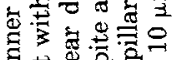

年

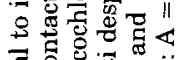

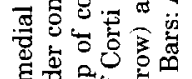

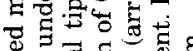

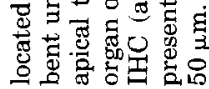
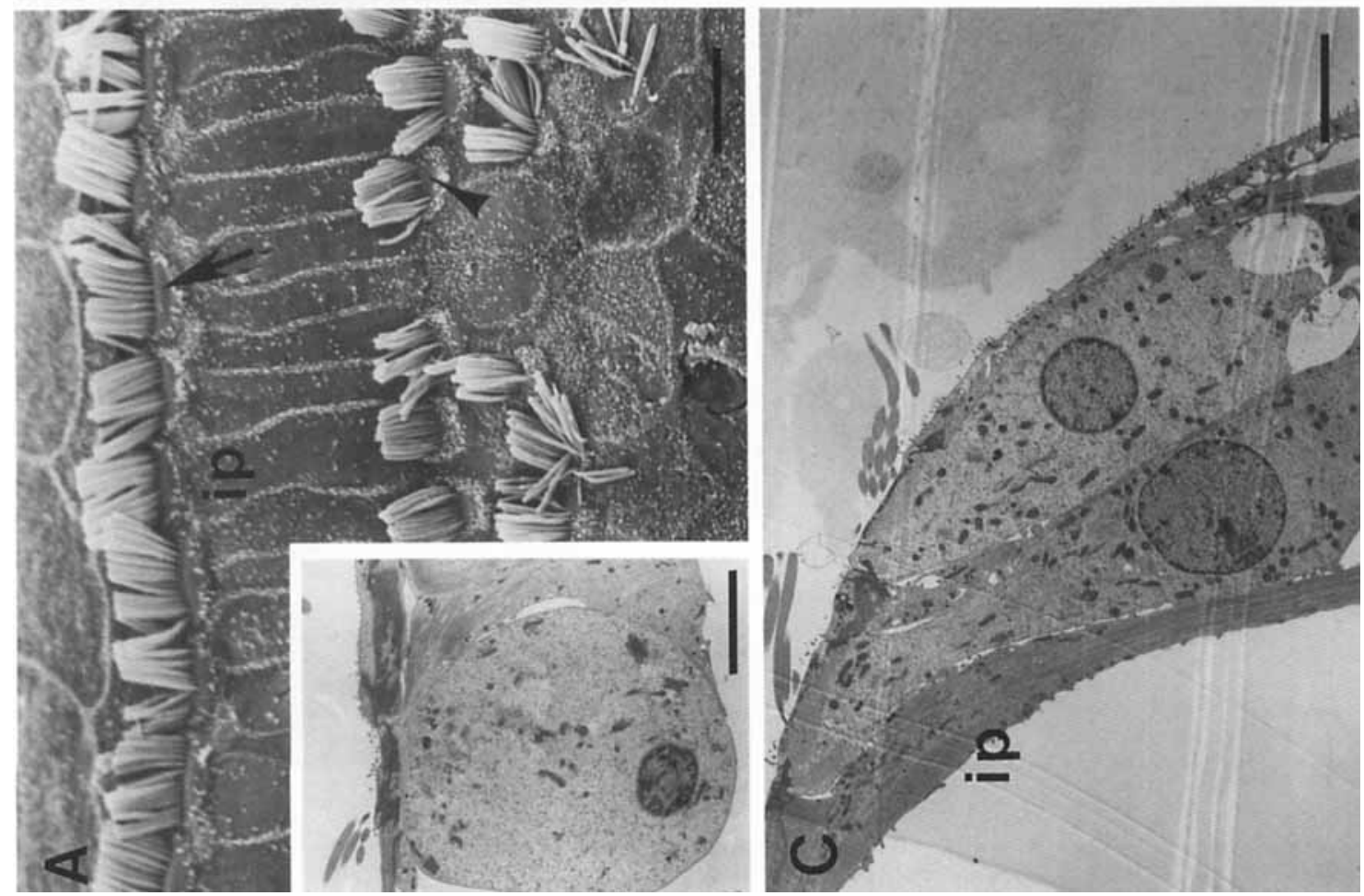

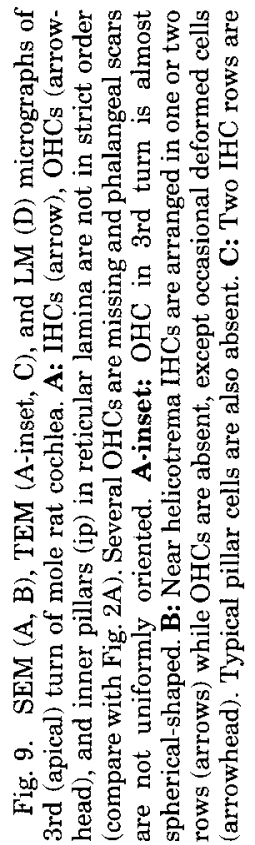



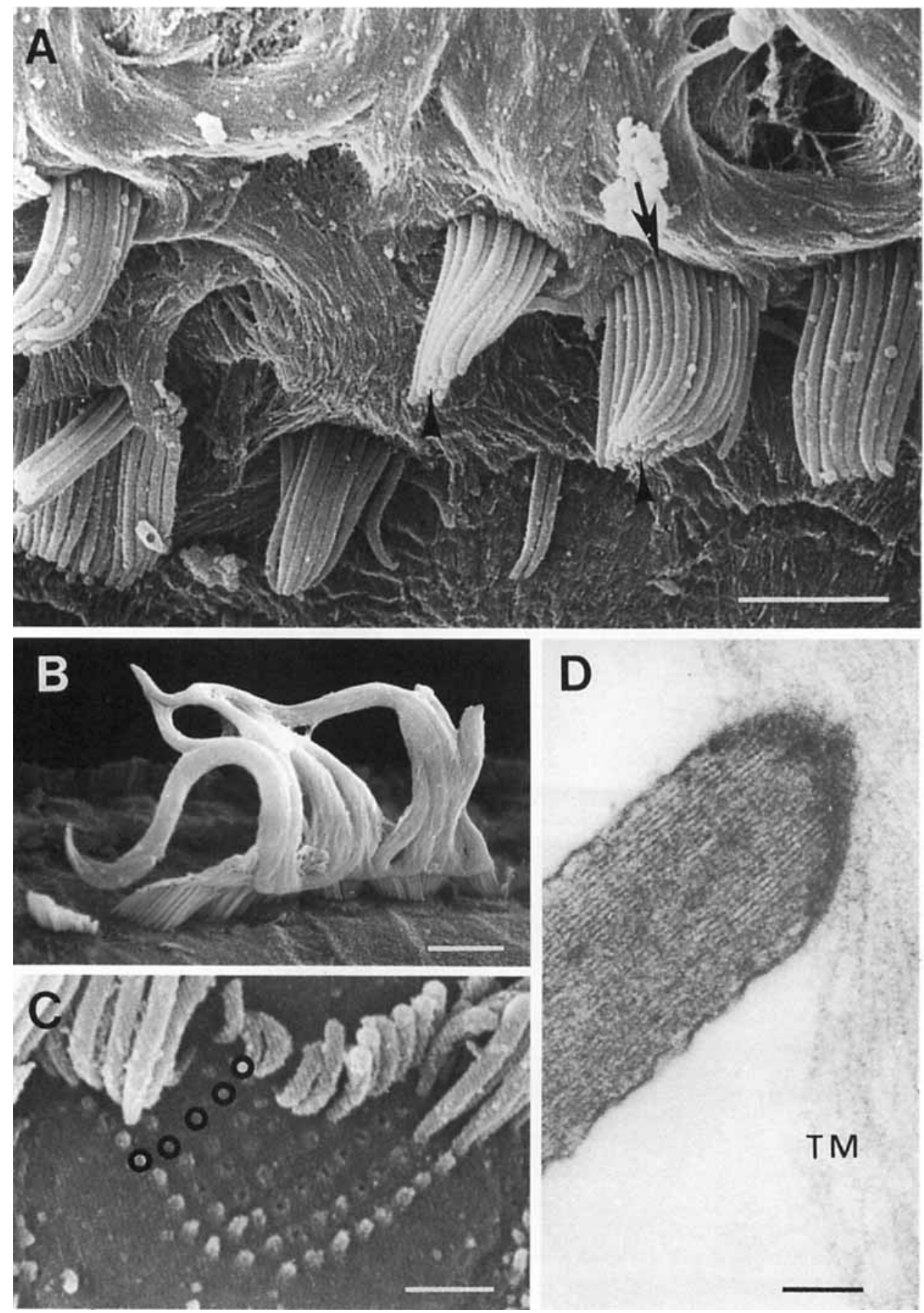

Fig. 10. SEM micrographs of tectorial membrane (TM) (A) and apical portion of OHCs (B and C), and TEM micrograph of stereocilia tip-TM contact (D). A: Underside of TM is rough and fibrillar. When lifted, OHC stereocilia (arrow), which are strongly embedded in TM, detach from anchoring site (arrowheads) in cuticular plate. B:

also similar to other mammals. IHCs are contacted by radial dendrites of type I ganglion cells (Spoendlin '73). The synapses are characterized by pre- and postsynaptic membrane densities and a presynaptic body surrounded by microvesicles. Below the IHCs, efferent endings, presumably from the lateral system, make axodendritic contacts with the radial afferent fibers. Mature IHCs are rarely
Large fibers from underside of TM remain attached to tips of stereocilia after TM removal in apical turn. C: Stereocilia from 4 out of 5 rows (circle for every row) are pulled up during TM removal in upper-basal turn OHC. D: Dense material in area of contact between stereocilia tip and TM. Bars: $\mathrm{A}=5 \mu \mathrm{m} ; \mathrm{B}=10 \mu \mathrm{m} ; \mathrm{C}=1 \mu \mathrm{m} ; \mathrm{D}=0.1 \mu \mathrm{m}$.

contacted by efferent endings directly (Pujol and Lenoir, '86). Thus, comparison of the IHC system to other mammals indicates that this system is rather stable in the face of evolutionary pressures. IHCs appear similar in low- and high-frequency mammals, as well as basal and apical cochlear regions. The presence of two IHC rows and the absence of $\mathrm{OHCs}$ in the apical end of the mole rat 

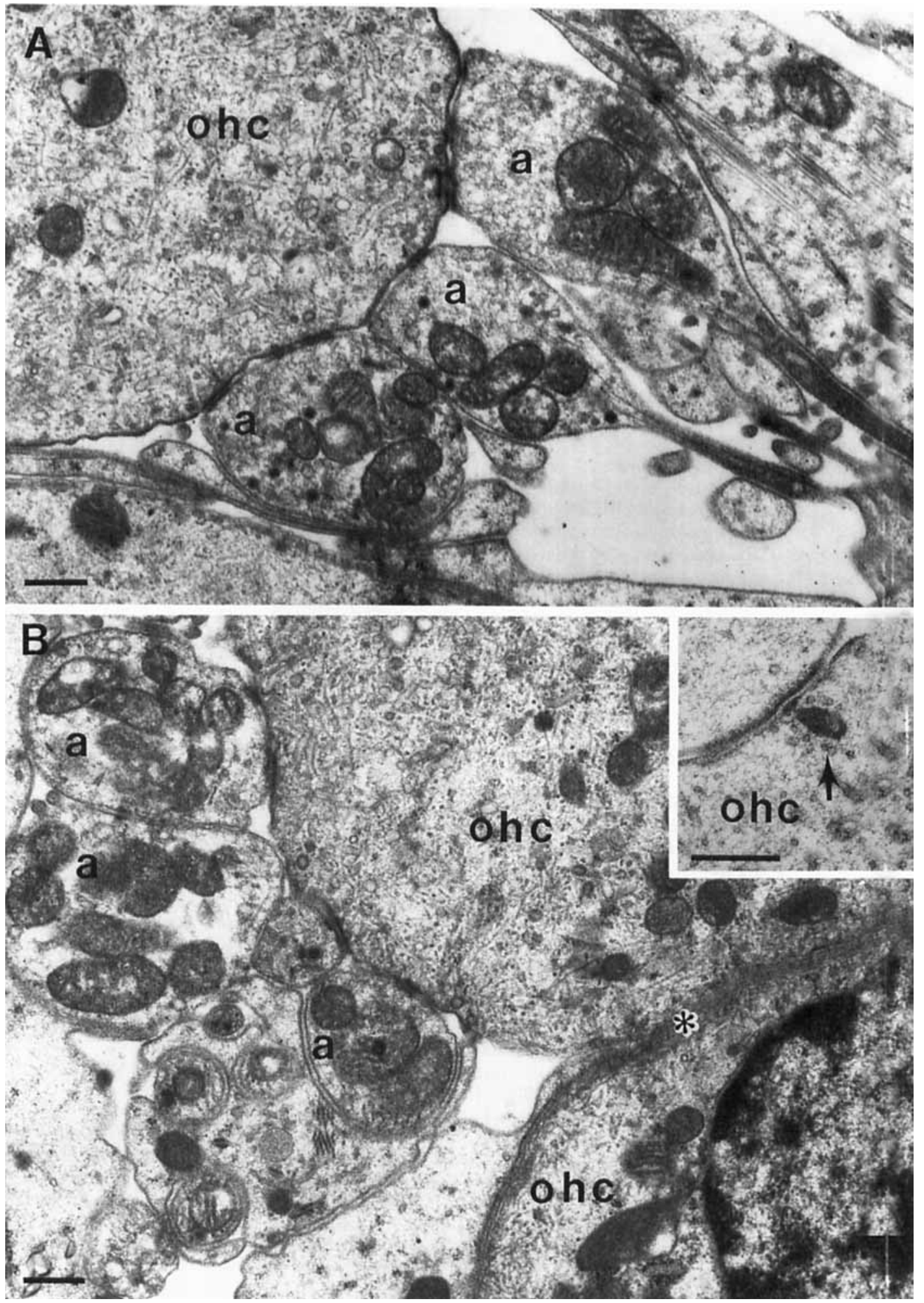

Fig. 11. TEM micrographs show nerve endings innervating middle and lower-apical turn OHCs (A and B, respectively). A: Three afferent terminals (a) synapse at base of OHC (ohc). No efferent terminals

present. B: Afferent synapses (a) on apical OHC which has contact (asterisk) with another OHC. Inset: Synaptic body opposing afferent synapse in OHC (ohe). Bars $=0.5 \mu \mathrm{m}$. 
cochlea suggests that IHCs play a major role while OHCs are not necessary for low-frequency hearing.

\section{Outer hair cells}

The morphology of OHCs differs from that in most mammals in several features, including size and organization of stereocilia, shape of the cell bodies, surrounding intercellular fluid, and innervation pattern. Equipped with such $\mathrm{OHCs}$, mole rats are able to detect low-frequency sounds, although it is not clear how the special structural features contribute to low-frequency hearing.

The length of OHCs and their stereocilia in the mole rat gradually increases along the cochlear duct from base to apex (Bruns et al., '88, and our unpublished measurements). Although such gradients are common among all studied mammals (Bohne and Carr, '85; Lim, '86), it is not understood why tall hair cells with tall stereocilia reside in the apex where low frequencies are mediated, whereas short cells with short stereocilia mediate high frequencies. Unlike those of other small mammals, mole rat stereocilia in the basal region are relatively tall, measuring 3-4 $\mu \mathrm{m}$. We speculate that tall stereocilia in basal $\mathrm{OHCs}$ reduce the mole rat's sensitivity for high-frequency auditory stimuli.

The number of rows of stereocilia on a given $\mathrm{OHC}$ is greater in the mole rat (five rows) than in mammals with higher-frequency hearing ranges such as cat, guinea pig, mouse, and bat (three rows). In addition to the mole rat, four or five rows of stereocilia were also observed in man and other primates. This finding may reflect adaptation to low-frequency hearing. Alternatively, in the mole rat this may reflect an immature stage of development, since developing mammalian OHCs have more stereocilia rows than mature OHCs (Lavigne-Rebillard and Pujol, '86; Lenoir et al., '87).

Mole rat OHCs have one layer of SSC along their lateral wall in all cochlear turns, similar to several other mammals including rat, mouse, bat, and man (Lim, '86; Vater et al., '91b). The SSC are connected to cytoplasmic microtubules and, via projections termed "arms" (Raphael and Wroblewski, '86) or "pillars" (Flock et al., '86), to the lateral plasma membrane. SSC are a conspicuous component of OHCs. It has been speculated that SSC have some role in the active biomechanical process in OHCs (see Brownell, '90, for review).

Mammalian OHCs are usually innervated by spiral afferent dendrities of type II ganglion cells and by efferent fibers from the medial system (Spoendlin, '73; Pujol and Lenoir, '86; Pujol et al., '86; Warr, '78). The afferent dendrites cross the floor of the tunnel of Corti and form small bouton-type endings with asymmetric postsynaptic densities on OHCs. The presynaptic area contains round synaptic vesicles (see Pujol and Lenoir, '86, for review). Compared with IHC-afferent synapses, mature OHCafferent synapses contain fewer vesicles and no synaptic bars. Presynaptic coated vesicles are attached to the $\mathrm{OHC}$ membrane and form endocytotic profiles (Pujol and Lenoir, '86). Medial efferent fibers traverse the tunnel of Corti at a point higher than the afferent fibers. Their terminals make large synapses with $\mathrm{OHCs}$ and contain a high density of clear spherical vesicles. Presynaptic vesicle clusters and postsynaptic cisternae typically underlie the entire synaptic region (Pujol and Lenoir, '86).

Synapses in the mole rat $\mathrm{OHC}$ region appear to be typical afferent synapses. In the apical turn they display small bouton-like presynaptic bodies, devoid of vesicles. Presynaptic bodies are common in developing but not mature OHCs. The presence of presynaptic bodies in apical but not basal $\mathrm{OHC}$ synapses is consistent with the generally immature structure of the apical region in the mole rat organ of Corti. Vesicle-containing terminals were occasionally seen on OHCs in the basal cochlea, but these terminals lacked high density clusters of clear spherical vesicles and postsynaptic cisternae. Therefore they were not typical efferent-OHC synapses. Future studies using histochemical methods will be needed to characterize the nature of these atypical synapses.

Myelinated nerve fibers in Rosenthal's canal of the mole rat appear ovoid or elongated in mid-modiolar sections, indicating that these fibers are not running in a radial direction, and therefore, they are most probably afferents rather than medial efferents. The absence of cross cut myelinated fibers in Rosenthal's canal suggests that only lateral efferents (unmyelinated) are present. In other mammals, when sectioned at the mid-modiolar plane, Rosenthal's canal would contain round (cross-sectioned) myelinated and nonmyelinated nerve fibers, corresponding to medial and lateral efferents, respectively.

Taken together, the morphology of the nerve endings, the type of synapses, the lack of upper-crossing tunnel fibers, and the shape of the fibers in Rosenthal's canal suggest that the medial efferent system in the mole rat is underdeveloped or absent. This finding is in accord with the scarcity of efferents in the apical cochlear region in other mammals (Iurato, '74; Altschuler and Fex, '86). These results also imply that the medial efferent system is not necessary for mammals that lack high-frequency sensitivity. However, no obvious relation appears between the absence of medial efferents and audible frequency range, since the horseshoe bat also lacks a medial efferent system.

From an evolutionary point of view, OHCs are younger and more specialized than IHCs. During ontogeny, OHCs undergo a phylogenetic stage of differentiation in which they resemble IHCs and their innervation is exclusively afferent (Lenoir et al., '80; Lavigne-Rebillard and Pujol, '86; see Rubel, '78, for review). Based on their morphology and their pattern of innervation, it is likely that the OHCs in the mole rat never complete their development and remain in a relatively undifferentiated state. This was especially evident in the apical turn, where OHCs appeared similar to IHCs in their shape and innervation pattern.

\section{Tectorial membrane}

Hardesty's membrane was not found throughout the TM of the mole rat cochlea. In the rat Hardesty's membrane is not seen in the apical region (Lenoir et al., '87) but in the bat it is present throughout the cochlea (Vater et al., '91a). This may suggest that the function of Hardesty's membrane is related to high-frequency hearing. The contacts between stereocilia-tips of OHCs and the TM in the mole rat cochlea are relatively stable despite the absence of Hardesty's membrane. It is not clear why firm stereocilia-TM attachments are beneficial for low-frequency hearing.

\section{Supporting cells}

Deiters cell bodies in the basal cochlea are large and closely surround the $\mathrm{OHC}$ base, as seen in many other mammals (Engström, '67; Kimura, '84). In the apical 
cochlea, the body region of Deiters cells appears slender and the area of contact with the OHCs appears small, as previously reported (Bruns et al., '88).

Deiters cells may also contribute to adaptational organization and structure. In the rat the phalangeal processes of Deiters cells reach the reticular lamina after extending obliquely and passing two or three OHCs and in the horseshoe bat one or two OHCs (our unpublished observation). The phalangeal processes of Deiters cells in the mole rat extend more obliquely and pass four or five OHCs before reaching the reticular lamina. This may influence the mechanical properties of the organ of Corti.

In the absence of OHCs and Deiters cells near the helicotrema, pillar cells remain the only mechanical support for the organ of Corti. It appears that pillar cells are capable of surviving without direct trophic influence from neighboring OHCs. This may be significant in understanding intercellular interactions in the organ of Corti during hair cell degeneration and scar formation. Raphael and Altschuler ('91) speculated that the survival of the organ of Corti depends on the presence of IHCs rather than OHCs. Indeed, the apical end of the mole rat cochlea presents evidence that IHCs and pillar cells survive in the absence of OHCs, suggesting that $\mathrm{OHCs}$ do not contribute to the survival of epithelial structures in the organ of Corti.

\section{Comparative function-structure correlation and the active biomechanical mechanism}

The mole rat hearing system is most sensitive between 0.5 and $1.0 \mathrm{kHz}$ (Bruns et al., ' 88 ). The best propagated frequency in underground tunnels is $0.5 \mathrm{kHz}$, and the main frequency of the mole rat courtship calls is in the same range (Heth et al., '86, '88). Comparative assessment of our findings on innervation, structure of hair cells, and the cytoarchitecture of the organ of Corti in the mole rat cochlea indicates that adaptation to low-frequency hearing does not require changes in IHCs but does involve a poorly differentiated $\mathrm{OHC}$ system.

$\mathrm{OHCs}$ are thought to modulate the sensitivity and the tuning of the cochlear partition by an active mechanism (Davis, ' 83 ). The active mechanism is probably modulated by the medial efferent system (Mountain, '80; Siegel and Kim, '82; Puel et al., '88). It is not clear to what extent the poorly differentiated $\mathrm{OHCs}$ of the mole rat are involved in an active mechanism. If an active mechanism does exist in the mole rat cochlea, it is most probably not under efferent influence.

\section{ACKNOWLEDGMENTS}

We acknowledge the excellent technical assistance provided by Wiveca Ring, Chantal Ripoll, Christina Sahlstrom, Pierre Sibleyras, Marie-Louis Spangberg, and Ann-Britt Wikström. We would like to thank Richard Altschuler, David Dolan, Joseph Hawkins, and Donna Martin for critical comments on contents and style.

\section{LITERATURE CITED}

Altschuler, R.A., and J. Fex (1986) Efferent neurotransmitters. In R. Aitschuler, R. Bobbin, and D. Hoffman (eds): Neurobiology of Hearing: The Cochlea. New York: Raven Press, pp. 383-396.
Bohne, B.A., and D.C. Carr (1985) Morphometric analysis of hair cells in the chinchilla cochlea. J. Acoust. Soc. Am. 77:153-158.

Bronchti, G., P. Heil, H. Scheich, and Z. Wollberg (1989) Auditory pathway and auditory activation of primary visual targets in the blind mole rat (Spalax ehrenbergi): I. 2-Deoxyglucose study of subcortical centers. J. Comp. Neurol. 284:253-274.

Brownell, W.E. (1990) Outer hair cell electromotility and otoacoustic emissions. Ear Hear. 11:82-92.

Bruns, V., M. Muller, W. Hofer, G. Heth, and E. Nevo (1988) Inner ear structure and electrophysiological audiograms of the subterranean mole rat, Spalax ehrenbergi. Hear. Res. 33:1-10.

Burda, H., V. Bruns, and E. Nevo (1989) Middle ear and cochlear receptors in the subterranean mole-rat Spalax ehrenbergi. Hear. Res. 39:225-230.

Davis, H. (1983) An active process in cochlear mechanics. Hear. Res. 9:79-90.

Engström, H. (1967) The ultrastructure of the sensory cells of the cochlea. J. Laryngol. Otol. 81:687-715.

Flock, A., B. Flock, and M. Ulfendahl (1986) Mechanisms of movement in outer hair cells and a possible structural basis. Arch. Otorhinolaryngol. 243:83-90

Haim, A., G. Heth, H. Pratt, and E. Nevo (1983) Photoperiodic effects on thermoregulation in a blind subterranean mammal. J. Exp. Biol. 107:5964

Heffner, R.S., and H.E. Heffner (1982) Hearing in the elephant (Elephas maximus): Absolute sensitivity, frequency discrimination, and sound localization. J. Comp. Physiol. Psychol. 96:926-944.

Heth, G., E. Frankenberg, and E. Nevo (1986) Adaptive optimal sound for vocal communication in tunnels of a subterranean mammal (Spalax ehrenbergi). Experientia 42:1287-1289.

Heth, G., E. Frankenberg, and E. Nevo (1988) "Courtship" call of subterranean mole rats (Spalax ehrenbergi): Physical analysis. J. Mammal. 69: $121-125$.

Iurato, S. (1974) Efferent innervation of the cochlea. In W.D. Keidel and W.D. Neff (eds): Handbook of Sensory Physiology, Vol. V/1, Auditory System. Berlin: Springer-Verlag, pp. 261-282.

Kawabata, 1., and Y. Nomura (1978) Extra internal hair cells. A scanning electron microscopic study. Acta Otolaryngol. 85:342-348.

Kimura, R.S. (1984) Sensory and accessory epithelia of the cochlea. In I. Friedmann and J. Ballantyne (eds): Ultrastructural Atlas of the Inner Ear. London: Butterworths \& Co., pp. 101-132.

Lavigne-Rebillard, M., and R. Pujol (1986) Development of auditory outer hair cell surface in human fetuses. A scanning electron microscopy study. Anat. Embryol. 174:369-377.

Lenoir, M., J.-L. Puel, and R. Pujol (1987) Stereocilia and tectorial membrane development in the rat cochlea. A SEM study. Anat. Embryol. 175:477-487.

Lenoir, M., A. Shnerson, and R. Pujol (1980) Cochlear receptor development in the rat with emphasis on development. Anat. Embryol. 160:253-262.

Lim, D.J. (1972) Fine morphology of the tectorial membrane. Its relationship to the organ of Corti. Arch. Otolaryngol. 96:199-215.

Lim, D.J. (1986) Functional structure of the organ of Corti: A review. Hear. Res. 22:117-146.

Mountain, D.C. (1980) Changes in endolymphatic potential and crossed olivocochlear stimulation alter cochlear mechanics. Science 210:71-72.

Nevo, E. (1979) Adaptive convergence and divergence of subterranean mammals. Annu. Rev. Ecol. Syst. 10:269-308.

Puel, J.-L., R.P. Bobbin, and M. Fallon (1988) An ipsilateral cochlear efferent loop protects the cochlea during an intense sound exposure. Hear. Res. 37:65-69

Pujol, R., and M. Lenoir (1986) The four types of synapses in the organ of Corti. In R. Altschuler, R. Bobbin, and D. Hoffman (eds): Neurobiology of Hearing: The Cochlea. New York: Raven Press, pp. 161-172.

Pujol, R., M. Lenoir, and M. Eybalin (1986) Synaptology of the cochlea: Different types of synapses, putative neurotransmitters and physiological implications. In R.J. Salvi, D. Henderson, R.P. Hamernik, and V. Colletti (eds): Basic and Applied Aspects of Noise-Induced Hearing Loss. New York: Plenum Press, pp. 43-53.

Rado, R., M. Himelfarb, B. Arensburg, J. Terkel, and Z. Wollberg (1989) Are seismic communication signals transmitted by bone conduction in the blind mole rat? Hear. Res. 41:23-30

Raphael, Y., and R.A. Altschuler (1991) Scar formation after drug-induced cochlear insult. Hear. Res. 51:173-184.

Raphael, Y., and R. Wroblewski (1986) Linkage of sub-membrane-cisterns 
with the cytoskeleton and the plasma membrane in cochlear outer hair cells. J. Submicroscop. Cyto1. 18:731-737.

Rubel, E.W. (1978) Ontogeny of structure and function in the vertebrate auditory system. In: M. Jacobson (ed): Handbook of Sensory Physiology, Vol. IX, Development of Sensory Systems. New York: Springer-Verlag, pp. 135-237.

Siegel, J.H., and D.O. Kim (1982) Efferent neural control of cochlear mechanics? Olivocochlear bundle stimulation affects cochlear biomechanical nonlinearity. Hear. Res. 6:171-182.

Spoendlin, H. (1973) Innervation of the cochlear receptor. In A. Moller (ed) Basic Mechanisms in Hearing. New York: Academic Press, pp. 185-230.
Vater, M., M. Lenoir, and R. Pujol (1992) Ultrastructure of the horseshoe bat's organ of Corti. I. Scanning electron microscopy. J. Comp. Neurol. (In press).

Vater, M., M. Lenoir, and R. Pujol (1992) Ultrastructure of the horseshoe bat's organ of Corti. II. Transmission electron microscopy. J. Comp. Neurol. (In press).

Warr, W.B. (1978) The olivocochlear bundle: Its origins and terminations in the cat. In R.F. Naunton and C. Fernandez (eds): Evoked Electrical Activity of the Auditory System. New York: Academic Press, pp. 43-65.

Wright, C.G. (1975) Cochlear innervation in the guinea pig. I. The inner spiral bundle region. Acta Otolaryngol. 80:220-229. 